\title{
Free and Nonprotein Amino Acids of Tetrahymena pyriformis
}

\author{
Chung Wi \\ From the Section of Biochemistry, Mayo Clinic and \\ Mayo Foundation, Rochester, Minnesota \\ and \\ James F. Hogg \\ From the Department of Biological Chemistry, University of Michigan, \\ Ann Arbor, Michigan
}

Received August 22, 1955

\section{INTRODUCTION}

In a previous study (1), the composition of total cellular amino acids of the ciliated protozoan, Tetrahymena pyriformis (formerly, T. geleii), was presented together with other pertinent data concerning the nitrogen metabolism of this organism. The present investigation was undertaken to obtain information on the free and nonprotein amino acids of this protozoan cell, inasmuch as the nonprotein nitrogen constitutes an unusually large fraction of the total nitrogen. These data make possible an evaluation of the relationship between the amino acid composition of the whole cell and that of the cellular protein. In addition, they provide a basis for comparison with results of similar investigations on other organisms.

\section{Experimental Procedures}

The identical cell preparation that was obtained by growing the peptone strain of $T$. pyriformis in a peptone medium, and designated as P-P in a previous study (1), was used in this investigation. Approximately $100 \mathrm{mg}$. of this cell preparation was suspended in $10 \mathrm{ml}$. of distilled water and dialyzed (2) against $20 \mathrm{ml}$. of distilled water at $4^{\circ} \mathrm{C}$. for $16 \mathrm{hr}$. Cellulose casing (27/32, Nojax, Visking Corporation) was used as the dialyzing membrane. An aliquot of the dialyzate was desalted with the apparatus of Astrup and associates (3) for $15 \mathrm{~min}$. The desalted dialyzate was dried in vacuo, and taken up in a small volume of $10 \% 2$-propanol. This con- 
centrate was used for the determination of free amino acids. Another aliquot of the dialyzate was hydrolyzed in boiling $6 \mathrm{~N}$ hydrochloric acid for $24 \mathrm{hr}$. The hydrolyzate was dried in vacuo to remove an excess of hydrogen chloride and then treated similarly for the determination of total dialyzable amino acids (nonprotein amino acids). Amino acids were determined by a paper-ehromatographic method of which the detailed procedure has been given elsewhere (4). Since the concentration of amino acids in the cell dialyzate varied widely, not all amino acids could be determined on one chromatogram. Chromatograms containing the 2-propanol concentrate equivalent to $10-45 \mu \mathrm{g}$. of $\alpha$-amino nitrogen were prepared. Only those amino acid spots which produced the optimal color intensity on a given chromatogram were cut out for the determination. In addition, asparagine and glycine were separated under the same conditions which were employed to separate lysine from arginine. The optical density from eluates of both asparagine and proline was measured at $400 \mathrm{~m} \mu$.

Dialyzates and hydrolyzates of the cell preparation were prepared at different times, and the entire analytic procedure was repeated. In paper chromatography of the amino acids, at least duplicate sheets of each sample were employed. The data presented in this study represent the average values obtained from these samples with average deviations no greater than $7 \%$ of the values.

Total $\alpha$-amino nitrogen was determined by the copper method (5). This method determines not only all amino acids which can be determined by the manometric ninhydrin method (6), but also amino acid amides, $\beta$-alanine, and simple peptides such as glutathione and carnosine. Hence, values of $\alpha$-amino nitrogen determined by this method are expected to be higher than those determined by the manometric ninhydrin method. However, neither method measures taurine.

\section{REsults}

The data concerning the free and nonprotein amino acids are presented in Table 1 . The content of the conjugated amino acids was calculated by obtaining the difference between the nonprotein and the free amino acids. In the hydrolyzed dialyzate of the cells, $96 \%$ of the total $\alpha$-amino nitrogen was accounted for by the amino acids determined. This fact, coupled with the absence of major unknown spots on the paper chromatogram, indicates that nearly all measurable ninhydrin-positive compounds, with the known exception of tryptophan, have been determined in the hydrolyzed dialyzate. In the unhydrolyzed cell dialyzate, however, only $79 \%$ of the total $\alpha$-amino nitrogen could be accounted for by the amino acids analyzed. The percentage could have been higher had the value of total $\alpha$-amino nitrogen not included $\alpha$-amino nitrogen of simple peptides which were not determined by the chromatographic procedure. For the same reason, the difference in the $\alpha$-amino nitrogen content between the nonprotein and the free amino acids does not fully represent the $\alpha$-amino nitrogen content of the conjugated amino acids. 


\section{TABLE I}

Free and Nonprotein Amino Acids and Related Compounds in Tetrahymena pyriformis

\begin{tabular}{|c|c|c|c|c|c|c|}
\hline \multirow{2}{*}{ Compound } & \multicolumn{2}{|c|}{ Frec } & \multicolumn{2}{|c|}{ Nonprotein } & \multicolumn{2}{|c|}{ Conjugated } \\
\hline & (A) & Per cent $t^{b}$ & (B) & Per cent $t^{b}$ & $(B-A)$ & Per cent ${ }^{c}$ \\
\hline & $m g . / g .^{a}$ & & $m g \cdot / g^{a}$ & & $m g \cdot / g^{a}$ & \\
\hline Alanine & 6.2 & 6.8 & 11.7 & 8.9 & 5.5 & 47.0 \\
\hline Arginine $^{d}$ & 10.6 & 6.0 & 11.4 & 4.4 & 0.8 & 7.0 \\
\hline Aspartic acid & 5.7 & 4.2 & 20.8 & 10.5 & 15.1 & 72.6 \\
\hline Asparagine & 3.2 & 2.4 & & & & \\
\hline Cystine & 0.8 & 0.7 & 1.5 & 0.8 & 0.7 & 46.7 \\
\hline Glutamic acid & 10.5 & 7.0 & 25.3 & 11.6 & 14.8 & 58.5 \\
\hline Glutamine & 1.8 & 1.2 & & & & \\
\hline Glycine & 4.7 & 6.1 & 16.8 & 15.0 & 12.1 & 72.0 \\
\hline Histidine & 2.2 & 1.4 & 4.3 & 1.9 & 2.1 & 48.8 \\
\hline Leucine-isoleucine & 16.8 & 12.6 & 22.9 & 11.8 & 6.1 & 26.6 \\
\hline Lysine & 8.3 & 5.6 & 9.0 & 4.1 & 0.7 & 7.8 \\
\hline Methionine & 1.2 & 0.8 & 2.4 & 1.1 & 1.2 & 50.0 \\
\hline Phenylalanine & 8.4 & 5.0 & 13.1 & 5.3 & 4.7 & 35.9 \\
\hline Proline & 4.0 & 3.4 & 7.0 & 4.1 & 3.0 & 42.9 \\
\hline Serine & 3.2 & 3.0 & 5.1 & 3.3 & 1.9 & 37.3 \\
\hline Taurine & 0.8 & & 1.5 & & 0.7 & 46.6 \\
\hline Threonine & 5.1 & 4.2 & 8.9 & 5.0 & 3.8 & 42.6 \\
\hline Tryptophan & $<0.5$ & & & & & \\
\hline Tyrosine & 6.0 & 3.2 & 9.6 & 3.6 & 3.6 & 37.5 \\
\hline Valine & 6.0 & 5.0 & 8.1 & 4.7 & 2.1 & 25.9 \\
\hline $\begin{array}{l}\text { Total } \alpha \text {-amino } \mathrm{N} \\
\text { Total }\end{array}$ & 14.3 & 78.6 & 20.8 & 96.1 & & \\
\hline
\end{tabular}

a Milligrams per gram of cells on a dry and ash-free basis.

${ }^{b}$ Per cent of total $\alpha$-amino nitrogen.

c Per cent of the nonprotein amino acid existing in the conjugated form.

${ }^{d}$ The values given are minimal (see text).

Stcin and Moore (7) have shown that considcrable quantities of arginine are lost during electrolytic desalting with the apparatus of Consden and co-workers (8), and that most of the loss is due to conversion into ornithine. The desalting apparatus of Astrup and associates (3), which was used in the present investigation, has greatly reduced the loss of arginine. Since the recovery of arginine added to the cell dialyzate before desalting was not investigated, the exact percentage of loss from the cell dialyzate during desalting could not be determined. The values for 
arginine given in Table I were calculated as they were actually determined. Hence, the true values may be approximately $20 \%$ higher than those reported in the table. The values for the free and nonprotein ornithine were estimated at 3.3 and $6.2 \mathrm{mg} . / \mathrm{g}$. cells, respectively, on a dry and ash-free basis. Since a part of the ornithine could have been derived from arginine during desalting, these values can be considered tentative only. However, the presence of ornithine in the cells was confirmed with the procedure of Chinard (9) in the basic effluent from a column of Dowex 2 (10) containing the neutral aqueous solution from a $60 \%$ ethanolic extract of the cells.

It is highly probable that free tryptophan was present in the cells. However, low concentrations of this amino acid in the tissues of the cat (11) and the rat $(12,13)$ and in human blood plasma (14) apparently explain the difficulty encountered in its accurate estimation by the chromatographic procedure. Hence, only the upper limit of free tryptophan could be determined. Perhaps the failure to detect other amino acids, such as $\alpha$-aminobutyric and $\gamma$-aminobutyric acids, $\beta$-alaninc, hydroxyproline, and citrulline, resulted from their low content in, rather than their absence from, the cells. The presence of a spot to the right of glutamic and aspartic acids on the chromatogram of the unhydrolyzed dialyzate and its disappearance after hydrolysis suggest the occurrence of phospho-ethanolamine. Its identity, however, was not confirmed. The difficulty in determining glutathione by paper chromatography has been reported (15). But if it is assumed that the increase in the cystine content after hydrolysis was derived solely from glutathione, the glutathione content would be estimated at $3.5 \mathrm{mg}$. $/ \mathrm{g}$. cells on a dry and ash-free basis.

On a molar basis, the six most abundant free amino acids in the cells are, in decreasing order, glutamic acid, alanine, "half" leucine-isoleucine, glycine, arginine, and lysine. On the other hand, the least abundant free amino acids are the sulfur-containing amino acids, methionine and cystine, and tryptophan. The data in Table I also show that asparagine and glutamine formed 21.2 and $12.2 \%$, respectively, of conjugated aspartic and glutamic acids. Hence, the amides constituted only a relatively small portion of the dicarboxylic amino acids present in the conjugated form.

According to the percentage of the nonprotein amino acid existing in the conjugated form, the amino acids may be classified into three groups. One group with a pcrcentage greater than 50, the "peptide-rich" amino 
acids, includes aspartic acid, glycine, and glutamic acid. A second group with a percentage less than 10, the "peptide-poor" amino acids, consists of arginine and lysine only. All other amino acids belong to the third group with a percentage between 25 and 50 . The low peptide content of arginine and lysine in the cells is in good agreement with that found in the muscle tissues of Crustacea and fish (16). The high content of conjugated aspartic acid, glutamic acid, and glycine has been observed also in the tissues of the cat (11).

The determination of the nonprotein amino acids of $T$. pyriformis has made possible the calculation of the protein-bound amino acids from the total amino acids of the cells (1). These results are given in Table II. It can be seen that the ratios of the total to protein-bound amino acids are fairly constant, namely, in the range from 1.4 to 2.1 , with the exception of glycine. It thus appears that the amino acid composition of the whole cell, with one exception, does reflect that of the cellular protein. The excellent correlation of the relative abundance of amino acids of crude mammalian protcins (17) to that of wholc protozoan cells

\section{TABLE II}

Quantitative Relationship in the Amino Acid Composition between the Whole Cell and the Cellular Protein of Tetrahymena pyriformis

Amino acid

Alanine

Arginine

Aspartic acid

Cystine

Glutamic acid

Glycine

Histidine

Leucine-isoleucine

Lysine

Methionine

Phenylalanine

Proline

Serine

Threonine

Tyrosine

Valine

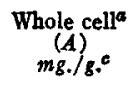

23

26

58

4.3

73

25

11

71

29

8.1

25

15

19

24

21

25

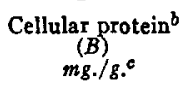

11.3

14.6

37.2

2.8

47.7

8.2

6.7

48.1

20.0

5.7

11.9

8.0

13.9

15.1

11.4

16.9
Ratio,

$(A) /(B)$

2.0

1.8

1.6

1.5

1.5

3.0

1.6

1.5

1.5

1.4

2.1

1.9

1.4

1.6

1.8

1.5

a From Table I of Wu and Hogg (1).

${ }^{b}$ Calculated by obtaining the difference between the amino acid content of the whole cell and that of the hydrolyzed dialyzate.

- Milligrams per gram of cells on a dry and ash-free basis. 
(1) can now be explained. On the other hand, the data in the present study indicate that a relationship in composition does not exist either between the total and the free amino acids, or between the protein-bound and the free amino acids of the cells. That no such relationship appeared to exist in other organisms has been indicated also $(13,15,18)$.

\section{Discussion}

There are some distinctive features in the free amino acid composition of $T$. pyriformis which are worthy of comment relative to higher animals. Free glutamic acid, glutamine, alanine, and glycine have been shown to be the most abundant amino acids in the tissues of the ox (19) and cow (20), the cat (11), the rat $(4,20)$, the rabbit, and the cock (21). Although the concentrations of free glutamic acid, alanine, and glycine were found to be high, the glutamine content of this protozoan is particularly low. At the same time, the asparagine content is almost twice as high. In contrast, the ratio of glutamine to asparagine has been estimated to be greater than 10 in cat tissues (11). Furthermore, while the amides constituted only a small portion of the conjugated glutamic and aspartic acids in the protozoan, increases in the content of these two amino acids after hydrolysis of the protein-free tissue extracts of the cat could be accounted for largely by the content of their respective amides (11). The very high content of free arginine in this organism is consistent with that in the muscle tissues of Crustacea (16) and in yeasts (22), but it is in contrast to the low concentration of this amino acid in tissues of higher animals $(4,11-13,19,20)$ and in bacteria (22) and algae (23). However, low concentrations of free and nonprotein methionine and, in a few instances, cystine have been observed also in mammalian tissues (4, 11-13, 19, 20, 24), Hirudinea (leeches), Gastropoda (whelks) (16), and yeasts (15).

In connection with the high content of conjugated glutamic acid, aspartic acid, and glycine in the cells, it is interesting to point out that large quantities of the same amino acids were excreted by the cells into the synthetic medium in the bound form (1). Hence, there appears to be a good correlation between a high peptide content of these amino acids within the cells and that excreted by the cells into the surrounding medium. Furthermore, high concentrations of conjugated glutamic acid, aspartic acid, and glycine have been found in the urine of human beings $(10,25)$, cats $(11)$, and rats (4). The striking resemblance in the pattern of excretion of conjugated amino acids between the protozoan and the mammals deserves special attention. 
The levels of the free and the nonprotein $\alpha$-amino nitrogen are 18.3 and $26.7 \%$, respectively, of the total nitrogen of the cells (1). These values are of the same order of magnitude as those estimated for yeasts (15), algae (26), and crustacean muscle (27), but they are considerably higher than those found in the tissues of guinea pigs and mice (28) and rats. ${ }^{1}$ The high content of nonprotein amino acids in Crustacea has been interpreted to be associated with the regulation of osmotic pressure (29). In addition, Lewis (30) suggested that the free dicarboxylic amino acids function as the internal anions to balance the internal inorganic cations. While the nonprotein amino acids in the protozoan might have certain regulatory functions, the mechanisms involved are undoubtedly quite different from those operating in the marine animals.

\section{Summary}

Paper chromatography was used to determine 20 amino acids and related compounds present in both the free and the nonprotein forms in Tetrahymena pyriformis. The most abundant free amino acids in the cells were found to be glutamic acid, alanine, leucine-isoleucine, glycine, arginine, and lysine. Free methionine, cystine, and tryptophan were present in the smallest quantities. A relatively large proportion of aspartic acid, glycine, and glutamic acid was found in the conjugated form, while nearly all nonprotein arginine and lysine occurred in the free form. In line with values observed in other invertebrates and microorganisms, the $\alpha$-amino nitrogen present in the free and the nonprotein forms constituted as high as a fifth and a fourth, respectively, of the total nitrogen of the protozoan cells.

A fairly constant ratio of the amino acid content of the whole cell to that of the cellular protein was obtained, which indicated that the amino acid composition of the whole cell reflects that of the cellular protein.

\section{REFERENCES}

1. WU, C., AND HogG, J. F., J. Biol. Chem. 198, 753 (1952).

2. Hamilton, P. B., ANd Archibald, R. M., Ind. Eng. Chem., Anal. Ed. 16, 136 (1944).

3. Astrup, T., Stage, A., And Orsen, E., Acta Chem. Scand. 5, 1343 (1951).

4. Wu, C., J. Biol. Chem. 207, 775 (1954).

5. WoIwod, A. J., Biochem. J. 45, 412 (1949).

6. Hamilton, P. B., and Van Slyke, D. D., J. Biol. Chem. 150, 231 (1943).

1 The values in per cent of total nitrogen for free $\alpha$-amino nitrogen in rat tissues were: plasma, 0.69; liver, 1.08; and muscle, 0.84 (Wu, C., unpublished data). 
7. Stein, W. H., And Moore, S., J. Biol. Chem. 190, 103 (1951).

8. Consden, R., Gordon, A. H., And Martin, A. J. P., Biochem. J., 41, 590 (1947).

9. Chinard, F. P., J. Biol. Chem. 199, 91 (1952).

10. Stein, W. H., J. Biol. Chem. 201, 45 (1953).

11. Taldan, H. H., Moore, S., and Stein, W. H., J. Biol. Chem. 211, 927 (1954).

12. Schurr, P. E., Thompson, H. T., Henderson, L. M., Williams, J. N., Jr., and Elyehjem, C. A., J. Biol. Chem. 182, 39 (1950).

13. Solomon, J. D., Johnson, C. A., Sheffner, A. L., ANd Bergeim, O., J. Biol. Chem. 189, 629 (1951).

14. Stein, W. H., ANd Moore, S., J. Biol. Chem. 211, 915 (1954).

15. Lindan, O., AND WoRK, E., Biochem. J. 48, 337 (1951).

16. Duchâtead, G., ANd Florkin, M., Arch. intern. physiol. 62, 487 (1954).

17. Dunn, M. S., Camien, M. N., Malin, R. B., Murphy, E. A., and Reiner, P. J., Univ. Calif. Publs. Physiol. 8, 293 (1949).

18. Roberts, E., Frankel, S., and Harman, P. J., Proc. Soc. Exptl. Biol. Med. 74, 383 (1950).

19. Astrup, T., Carlström, G., and Stage, A., Acta Physiol. Scand. 24, 202 (1951).

20. WALKER, D. M., Biochem. J. 52, 679 (1952).

21. Duchâteau, G., and Florkin, M., Arch. intern. physiol. 62, 205 (1954).

22. TAYLOR, E. S., J. Gen. Microbiol. 1, 86 (1947).

23. Courson, C. B., Chemistry \& Industry 1953, 971.

24. Wu, C., and Bollman, J. L., J. Biol. Chem. 210, 673 (1954).

25. Mürina, D., Z. physiol. Chem. 297, 61 (1954).

26. Channing, D. M., and Young, G. T., J. Chem. Soc. 1953, 2481.

27. Duchâteau, G., Florkin, M., and Sarlet, $H$., Arch. intern. physiol. 62, 512 (1954).

28. Christunsen, H. N., Strreicher, J. A., and Elbinger, R. L., J. Biol. Chem. 172,515 (1948).

29. Camien, M. N., Sarlet, H., Duchâteau, G., and Florkin, M., J. Biol. Chem. 193, 881 (1951).

30. Lewis, P. R., Biochem. J. 52, 330 (1952). 